\title{
Unilateral Creutzfeldt-Jakob Disease Presenting as Rapidly Progressive Aphasia
}

\author{
Andrew Kirk and L.C. Ang
}

\begin{abstract}
A 64-year-old man presented with a three day history of progressive Broca's aphasia, followed within 3 weeks by exclusively right-sided myoclonus, rigidity, and dystonia. Within 4 weeks he was globally aphasic. He died within 7 weeks of onset. In the final week, rigidity and myoclonus L.ecame bilateral. CT and MRI were normal. SPECT showed diminished perfusion of the left hemisphere. EEG showed periodic discharges on the left. At autopsy, there were marked cortical spongiform change, neuronal loss, and gliosis throughout the left hemisphere and in the right occipital cortex. Elsewhere in the right hemisphere, spongiform change was non-existent to minimal. There was moderate spongiform change in the molecular layer of the cerebellar cortex, much more marked on the left. Clinical and pathological unilateral cerebral predominance extended to the ipsilateral cerebellum. Creutzfeldt-Jakob disease is an important consideration in patients with rapidly progressive unilateral cerebral signs associated with a movement disorder.
\end{abstract}

\begin{abstract}
Résumé: Aphasie progressant rapidement comme tableau initial chez un patient atteint de CreutzfeldtJakob unilatéral. Un homme âgé de 64 ans a consulté pour une aphasie de Broca ayant progressé sur une période de trois jours, suivie trois semaines plus tard par des myoclonies, de la rigidité et de la dystonie localisées exclusivement à l'hémicorps droit. Quatre semaines après le début de la maladie, il presentait une aphasie globale et il est décédé trois semaines plus tard, soit sept semaines après le debut de la maladie. Pendant la dernière semaine de sa maladie, la rigidité et les myoclonies sont devenues bilatérales. La tomodensitométrie et la résonance magnétique nucléaire etaient normales alors que le SPECT a montré une diminution de la perfusion à l'hémisphère gauche. L'EEG a montré des décharges périodiques à gauche. A l'autopsie, it existait des modifications spongiformes corticales importantes, une perte neuronale et de la gliose dans tout l'hémisphère gauche et dans le cortex occipital droit. Ailleurs dans l'hémisphère droit, les modifications spongiformes étaient absentes ou minimes, alors qu'elles étaient modérées dans la couche moléculaire du cortex cérébelleux, surtout à gauche. La prédominance unilatérale clinique et anatomopathologique s'étendait au cervelet ipsilatéral. La maladie de Creutzfeldt-Jakob est un diagnostic qu'il est important de considérer chez les patients qui présentent des signes d'atteinte cérébrale unilatérale qui progressent rapidement et qui sont accompagnés d'un désordre du mouvement.
\end{abstract}

Can. J. Neurol. Sci. 1994; 21: 350-352

While slowly progressive aphasia in adults is often attributable to Alzheimer's disease, Pick's disease, or primary progressive aphasia, ${ }^{\prime}$ aphasia that presents acutely and progresses rapidly is most often the result of a stroke. In this report we describe a patient with Creutzfeldt-Jakob disease with predominantly left hemisphere involvement who presented initially with rapidly progressive Broca's aphasia.

\section{Case Report}

A 64-year-old right-handed retired salesman was admitted to hospital elsewhere on June 5, 1992 because of a three day history of difficulty finding words. This was associated with a mild headache. About 6 months previously he had begun to complain of headaches and seemed to his family to be more irritable than usual. In retrospect they felt that in about February, 1992 he began having mild intermittent difficulty finding words but otherwise seemed well until this word finding difficulty became much worse a few days before his admission to hospital.
Past history was positive for Crohn's disease. He had had a cholecystectomy many years previously. There was a long history of back pain for which he had taken numerous homeopathic medicines and "intravenous horse liniment" administered in Texas in 1980. There was a past history of heavy drinking but this had not been a problem for a decade.

The patient's father had died of leukemia in his 70's. His mother was one of 10 siblings, 2 of whom were said to have had Alzheimer's disease. The patient had 5 sisters, all well. He had 5 children, one of whom had polycystic kidney disease.

From the Division of Neurology, Royal University Hospital, University of Saskatchewan Saskatoon (A.K.) and the Department of Pathology (Neuropathology), Sunnybrook Health Science Centre, University of Toronto, Toronto (L.C.A.).

RECEIVED JANUARY 3, 1994. ACCEPTED IN FINAL, FORM JUNE I, 1994.

Presented in part at the 28th Canadian Congress of Neurological Sciences, June 18. 1993, Toronto. Ontario.

Reprim request to: Andrew Kirk, Division of Neurology, Royal University Hospital, 103 Hospital Drive, Saskatoon. Saskatchewan. Canada S7N 0W8 
He was admitted for investigation and thought initially to have had a stroke. On June 8 , he was first seen by a neurologist. He was felt to have Broca's aphasia and slightly brisker muscle stretch reflexes on the right than on the left.

Over the next month in hospital there was marked deterioration in his language abilities. He became more unsteady and began to stumble while walking. His right arm became tremulous and began to assume odd postures.

On first assessment at Royal University Hospital on July 3, he was alert, cooperative and attentive but at times rather childlike, having to be coaxed by his son to continue with the examination. His conversational speech was limited mainly to single words, and his most frequent utterance was an emphatic but not always appropriate "yes." Occasionally he produced nonfluent dysarthric utterances which were longer. His longest sentence was produced when he was shown dice and asked what they were for. He hesitantly replied, "you hold it...then you rest it." He could not name, saying "yes" or "well" when shown objects or pictures. He could not repeat. He could not follow commands and answered "yes" to all questions. He thus had global aphasia. He would not copy movements demonstrated by the examiner but had no difficulty dressing and undressing himself using both hands. When asked to write or draw he produced a meaningless scrawl. He could not read. He did not blink readily to threat in the right visual field although he did to threat from the left. Cranial nerves were normal. There was lead-pipe rigidity of the right arm and leg. Tone was normal on the left. Spontaneous myoclonus was frequently seen in the right arm and leg, never on the left. His right hand often assumed dystonic postures. Strength was normal. Sensory examination was normal for pinprick. Reflexes were 2+ symmetrically. Plantar responses were flexor. Coordination was normal. Gait was unsteady due to his unilateral rigidity.

He continued to deteriorate and by July 15 had diffuse rigidity and bilateral and generalized myoclonus. By July 19 he was comatose. He died on July 21 , less than 7 weeks after first seeking medical attention.

\section{INVESTIGATIONS}

CT and MRI scans were normal. HMPAO-SPECT scan showed diffusely diminished perfusion of the left cerebral hemisphere. EEG recorded 3 weeks into his illness showed left temporal delta and a periodic pattern of spike and sharp wave discharges predominantly in the left hemisphere every one to two seconds. Some of these discharges were associated with myoclonus clinically. Biochemical and hematologic investigations were all normal.

\section{Pathology}

Internal examination was restricted to the brain which appeared grossly normal. Microscopically, the cerebral white matter was unremarkable. Spongiform change was minimal in right frontal, cingulate, parietal, and temporal cortices; moderate in the left prefrontal, cingulate, and left and right visual cortex; and marked in the left temporal, parietal, and posterior frontal cortices. Spongiform change was also noted in the subicula, more marked on the left. Spongiform change was minimal in the basal ganglia and thalamus.

The degree of astrocytosis and neuronal loss in the various cortical areas roughly paralleled the severity of spongiform change. In the most severely affected cortical areas such as the left sensorimotor cortex, there was marked neuronal loss throughout layers II to VI with only occasional large pyramidal cells remaining (Figure 1). In the left temporal cortex, neuronal loss was most marked in layers II to $\mathrm{V}$ and in the left cingulate cortex, only layers III and IV showed significant neuronal loss. In all the involved cortical areas, there was astrocytosis in the

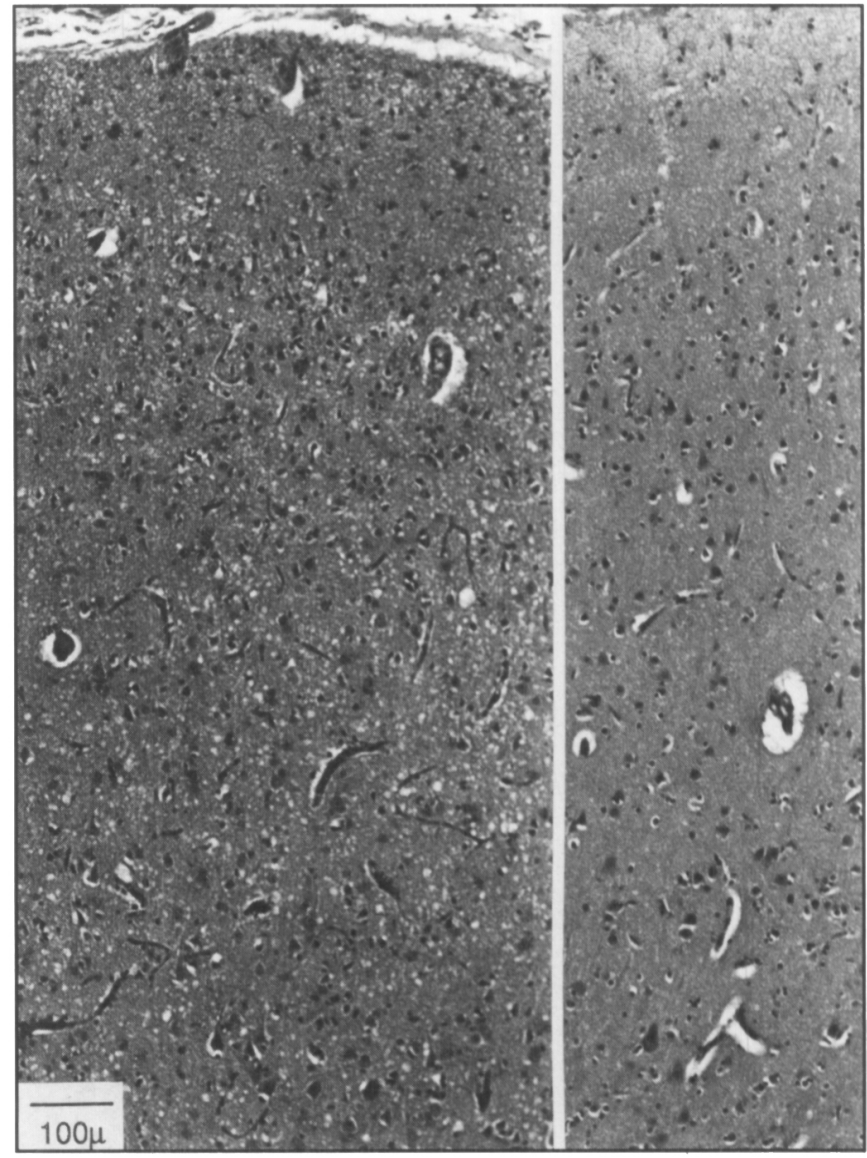

Figure 1: Comparison of the left (left side of figure) and right (right side of figure) sensorimotor cortices reveals spongiform change accompanied by neuronal loss and astrocytosis predominantly on the left (Hematoxylin-eosin, original magnification $x 10$ ).

molecular layer which was also affected by the spongiform change.

Amyloid plaques and senile plaques were noted throughout the cortex and were most numerous in the left sensorimotor cortex although not in sufficient concentration for a diagnosis of Alzheimer's disease. Neurofibrillary tangles were hardly seen. Few plaques were noted in the hippocampi.

Moderate spongiform change was noted in the molecular layer of the cerebellar hemispheres, again much more marked on the left side. There was scattered Purkinje cell dropout in the left cerebellar cortex. No plaques were seen in the cerebellum. In the brainstem, slight spongiform change was seen only in the periaqueductal gray matter of the midbrain.

\section{Discussion}

Although Creutzfeldt-Jakob disease (CJD) often presents initially with symptoms suggestive of focal disease, it is distinctly rare to see such unilateral predominance of the clinical, electroencephalographic, and pathologic findings. In a review of 150 autopsied cases, neuropathology was diffuse, even in cases that initially presented with symptoms and signs suggestive of unilateral disease. ${ }^{2}$ Several authors have described predominantly unilateral clinical findings with either symmetric pathology or no mention of any asymmetry. ${ }^{3-6}$ The first case of predominantly 


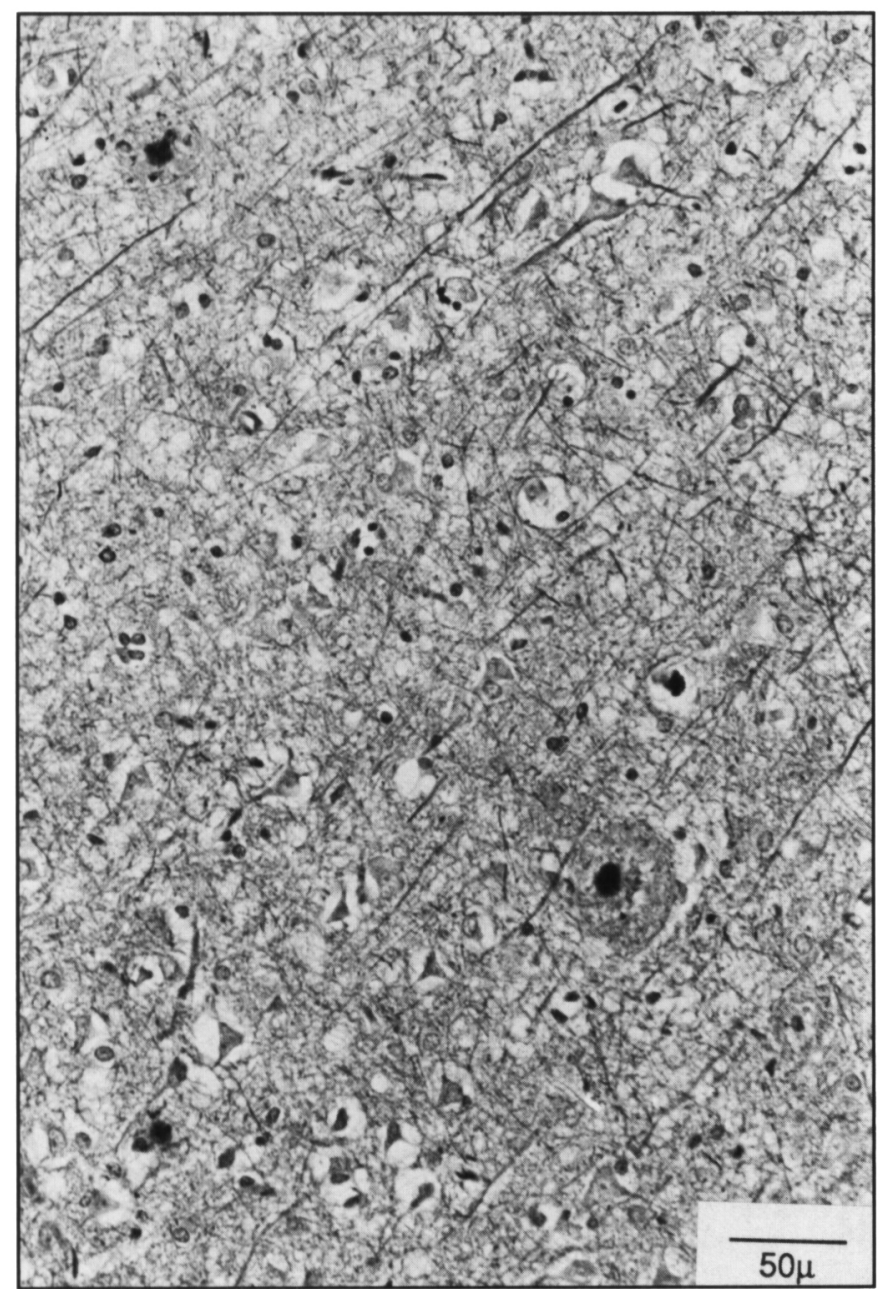

Figure 2: Frontal cortex showing three senile plaques with amyloid core (Bielschowsky, original magnification $\times 20$ ).

unilateral CJD was reported by Yamanouchi et al. ${ }^{7}$ Their case was also left-sided but differed from the present case in that the predominant unilaterality of the pathology did not extend to the cerebellum which was spared.

Mandell et al. described a patient with a 1 year course who presented with a fluent rather than a nonfluent aphasia. ${ }^{8}$ They examined only one side of the brain so could not comment on laterality of the pathology. They suggested that the fluency of their patient's aphasia might be useful in making a distinction between CJD and primary progressive aphasia ${ }^{1.9}$ but the present case demonstrates that CJD may also present with nonfluent aphasia.

It is unclear how the pathology of CJD can be so lateralized in rare instances. Like the patient of Yamanouchi et al., our patient survived less than two months after presentation. Had these patients survived longer, it is possible that the pathological changes could have become more generalized. However, the vast majority of patients with a short course have more symmetric pathology. ${ }^{2}$

Pathologically, our patient had widespread spongiform changes in at least one-half of the brain in contrast to the much more focal changes seen in previous cases of progressive aphasia without dementia where the pathology is generally restricted to the left inferior frontal and superior temporal regions. ${ }^{10}$ Our patient's rapid clinical deterioration was not consistent with the syndrome of slowly progressive aphasia. Pick's disease is also unlikely because of the absence of typical lobar atrophy and Pick bodies. Though senile plaques are noted in many regions of neocortex in our patient these are insufficient in number for the diagnosis of Alzheimer's disease and neurofibrillary tangles are very scarce.

It is not known how the disease process spreads through the nervous system. The unique left cerebral and cerebellar predominance in this case suggests that it is not necessarily transmitted along white matter pathways in which case one would have expected the cerebellar pathology to be mainly contralateral to the cerebral pathology.

Initially, this patient was thought to have had a stroke. The infectious nature of CJD makes it important to consider it in the differential diagnosis of rapidly progressive focal cerebral signs associated with a movement disorder.

\section{ACKNOWLEDGEMENTS}

Supported by grants to Andrew Kirk from the University of Saskatchewan College of Medicine and Saskatchewan Health Services Utilization and Research Commission. We thank Dr. Peter Davidson for referring this patient.

\section{REFERENCES}

1. Mesulam MM. Slowly progressive aphasia without generalized dementia. Ann Neurol 1982; 11: 592-598.

2. Kirschbaum WR. Jakob-Creutzfeldt Disease. New York, NY, American Elsevier, 1968.

3. Davison C, Rabiner AM. Spastic pseudosclerosis (disseminated encephalomyelopathy: corticopallidospinal degeneration). Arch Neurol Psychiatry, 1940; 44: 578-598.

4. Zieger A, Vonofakos D, Vitzthum HG. Creutzfeldt-Jakobschen krankheit: das Computertomogramm in korrelation Klinischen, Elektroenzephalographischen und Neuropathologischen befunden. Nervenarzt 1981; 52: 685-691.

5. Au WF, Gabor AJ, Vijayan N, Markand ON. Periodic lateralized epileptiform complexes (PLEDs) in Creutzfeldt-Jakob disease. Neurology 1980; 30: 611-617.

6. Shuttleworth EC, Yates AJ, Paltan-Ortiz JD. Creutzfeldt-Jakob disease presenting as progressive aphasia. J Nat Med Assoc 1985; 77: 649-656.

7. Yamanouchi H, Budka H, Vass K. Unilateral Creutzfeldt-Jakob disease. Neurology 1986; 36: 1517-1520.

8. Mandell AM, Alexander MP, Carpenter S. Creutzfeldt-Jakob disease presenting as isolated aphasia. Neurology 1989; 39: 55-58.

9. Chawluk JB, Mesulam MM, Hurtig H, et al. Slowly progressive aphasia without generalized dementia: studies with positron emission tomography. Ann Neurol 1986; 19: 68-74.

10. Kirshner MS, Tanridag O, Thurman LK, Whetsell wO. Progressive aphasia without dementia: two cases with focal spongiform degeneration. Ann Neurol 1987; 24: 537-542. 